\title{
Series Hybrid Active Power Filter For Power Quality Improvement in Distribution System
}

\author{
Kumar Reddy Cheepati ${ }^{*}$, Sardar $\mathrm{Ali}^{2}$ and Suraya Kalavathi $\mathrm{M}^{3}$

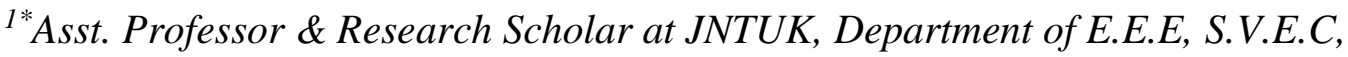 \\ A. Rangampet, Tirupathi, India \\ ${ }^{2}$ Professor \& Principal, Department of E.E.E, RITS, Chevella, India \\ ${ }^{3}$ Professor, Department of E.E.E, JNTU College of Engineering, JNTU, \\ Kukatpalli, Hyderabad, India \\ Kumarreddy98@gmail.com,dr.salisawcc@gmail.com,munagala12@yahoo.co.in
}

\begin{abstract}
The term power quality usually refers to voltage quality rather current quality. Maintaining voltage quality is the responsibility of utilities and maintaining current quality is the responsibility of the consumers connected to different loads. The harmonic current due to the nonlinear loads flows through the system impedance that causes disturbance to the voltage waveform. In this proposed research, a series hybrid active power filter was designed to eliminate both current and voltage harmonics. To eliminate current harmonics a double tuned filter was designed and for elimination of voltage harmonics series active filter was designed. MATLAB simulation results validates that series hybrid active power filter can eliminate both voltage and current harmonics in an effective manner as compared to earlier techniques.
\end{abstract}

Keywords: Double Tuned Filter; Harmonics; Series Active Filter; Nonlinear Load; Voltage Quality

\section{Introduction}

Concern about the power quality is increasing day by day as power system becoming more complex and it is difficult to deliver good quality of power to large loads. Power quality is one of the popular topics in the power industry since the late 1980's [1]. As per IEEE Recommendations for Power Quality standard (IEEE Std 1159-2009), the Power quality is termed as "powering and grounding sensitive load equipment in such a way that it is suitable for working of the equipment [2]". There are so many power quality issues like voltage sag, swell, interruptions, transients, noise, voltage fluctuations, under voltage, over voltage, DC offset, harmonics, inter harmonics, sub harmonics etc. Harmonics are the integral multiples of fundamental frequency which causes due to the nonlinear loads like power electronic devices, saturation devices, arc furnaces etc. Harmonics are classified into positive sequence, negative sequence and zero sequence components. Based on symmetry harmonics are classified as even and odd harmonics. Even harmonics cancels each other due to the symmetry of the waveform. Odd Harmonics are classified into positive sequence, negative sequence and zero sequence components. The positive sequence harmonics rotates in the same direction as original balanced fundamental power supply. The order of positive sequence harmonics are 1,7,13 etc., the negative sequence harmonics rotate in the direction opposite to the original balanced fundamental power supply. The order of negative sequence harmonics are 5, 11, 17 etc., the zero sequence harmonics does not have any phase displacement and rotation. The order of zero sequence harmonics are odd multiples of third harmonic frequency i.e.,

* Corresponding Author 
3,9,15 etc. Many advances in power quality improvement has been taken place but most of the techniques concentrated only on the elimination of current harmonics than voltage harmonics. Voltage harmonics are one of the important power quality issues which should be maintained purely sinusoidal to improve the power quality at the utility side. Higher order current harmonics causes more distortion in voltage wave form than lower order current harmonics. Current distortion mainly caused due to the nonlinear loads but voltage distortion caused by the current distortion and also by many other reasons like shunt capacitor switching, resonance condition etc., reducing current harmonics does not mean that reducing voltage harmonics in proportion to that. In general power quality refers to the voltage quality since, maintaining voltage quality is very important for the utility to meet the customer expectations. In this proposed research a double tuned shunt passive filter was designed to reduce the current harmonics and series active powers filter with instantaneous (or) p-q control technique was used to improve the voltage waveform at the terminals of the supplying load. So, it must be compulsory to solve the harmonic problems caused by that non-linear equipment which are already installed at various locations. This proposed research paper is divided into six chapters, Chapter-1 deals with introduction, Chapter- 2 deals with the block diagram of series hybrid active power filter, Chapter-3 deals with mathematical model of double tuned shunt passive filter, Chapter-4 deals with the design of series active power filter, Chapter-5 deals with results and discussions, Chapter-6 deals with conclusions.

\section{Topology of Series Hybrid Active Power Filter}

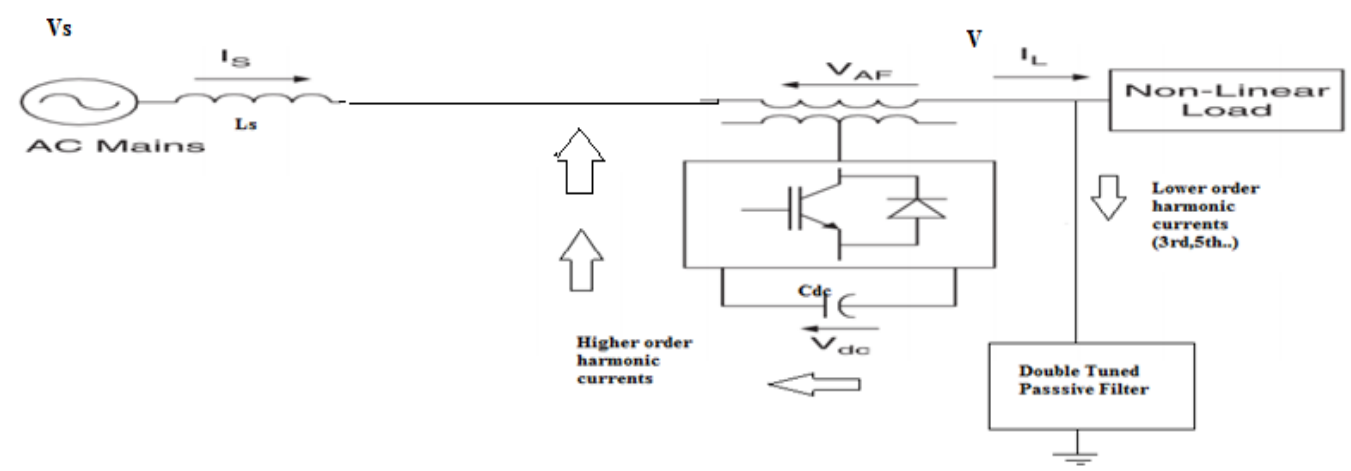

Figure 1. Block Diagram of Series Hybrid Active Power Filter.

From the Figure 1 series hybrid active filter consists of source which is connected to a nonlinear load (like bridge rectifiers, adjustable speed drives, arc furnaces etc.), a double tuned shunt passive filter connected in shunt with the system and a series active power filter with $\mathrm{p}-\mathrm{q}$ control technique is connected through coupling transformer. When a nonlinear load is connected to the supply, it draws a non-sinusoidal current from the supply. This non-linear current flows through the system impedance causes voltage distortion in the supply side. When there is a voltage distortion in the fundamental sinusoidal wave there is injection of current harmonics into the system. The objective of this proposed research is to say the importance of eliminating voltage harmonics in distributed system by series active power filter and various causes of voltage harmonics. Majority of the voltage harmonics are due to the current harmonics but not only by current harmonics alone, there are so many sources of voltage distortion like shunt 
capacitor switching and resonance conditions [3]. In this proposed research a double tuned passive filter was used than two parallel connected single tuned filters for better performance in eliminating two lower order current harmonics. With double tuned passive filter there is considerable reduction of total harmonic current distortion but the total voltage harmonic reduction is not up to the standard level as mentioned in the power quality standards. As mentioned already, there are many reasons to distort the voltage waveform, only by eliminating current harmonics, it is impossible to bring down the voltage to the acceptable level (purely sinusoidal), so a series active power filter is necessary to reduce the voltage harmonics. For connecting a series active power filter to the system, three isolation transformers with suitable KVA rating is necessary [4].

The effective elimination of both voltage and current harmonics can be done by the use of proposed series hybrid active power filter.

\section{Design of Double Tuned Shunt Passive Filter}

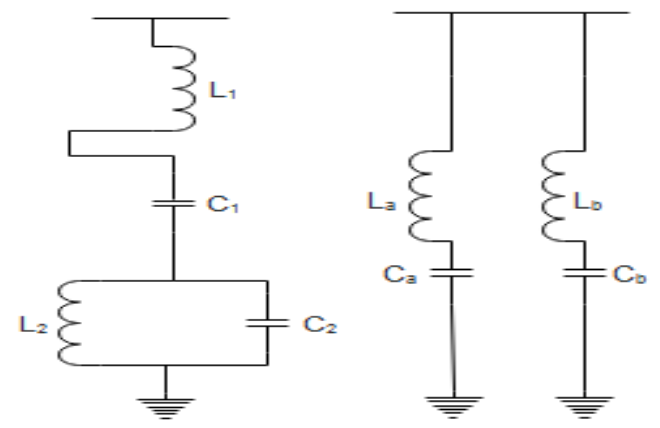

\section{Figure 2. Double Tuned Passive Filter \& Equivalent Single Tuned Passive Filters}

As shown in Figure 2, a double tuned filter having a series resonant and shunt resonant circuit [3]. It can filter two lower order $\left(3^{\text {rd }}, 5^{\text {th }}, 7\right.$ th etc. $)$ harmonics with a single circuit whereas for single tuned, it requires two separate parallel circuits. The series circuit gives series resonant frequency $\left(w_{s}\right)$ and parallel circuit gives parallel resonant frequency $\left(w_{p}\right)$. These two resonance frequencies can filter two dominant lower order current harmonics from the power system with single circuit. Double tuned passive filter gives better performance when compared to the two single tuned passive filters [4]. In this proposed research, by using parameters of two single tuned filters, the double tuned filter was designed. At resonant frequencies, the reactance of inductor is equal to the reactance of a capacitor. The double tuned passive power filter provides low impedance path to the two lower order current harmonics [4].

The impedance versus frequency curve is given by Figure 3 


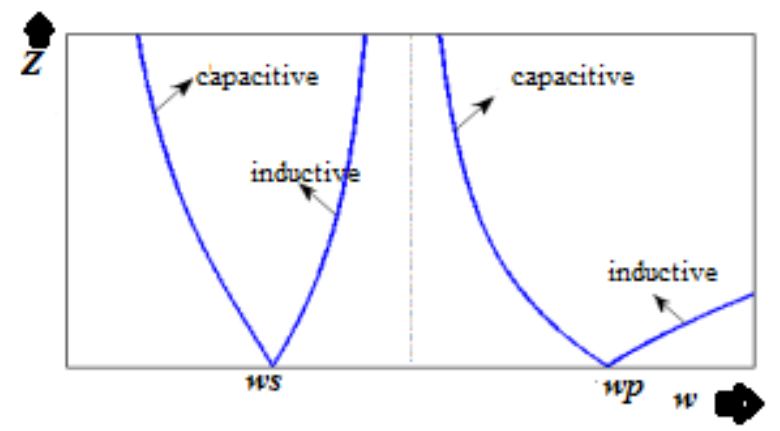

Figure 3. Characteristics of Double Tuned Filter

\subsection{Design Procedure:}

The series circuit impedance is

$Z_{s}=j w L_{1}+\frac{1}{j w C_{1}}$

The parallel circuit impedance is

$Z_{p}=\left(j w C_{2}+\frac{1}{j w L_{2}}\right)^{-1}$

The total impedance is

$Z=j w L_{1}+\frac{1}{j w C_{1}}+\left(j w C_{2}+\frac{1}{j w L_{2}}\right)^{-1}$

$Z=\frac{\left(1-\frac{w^{2}}{w_{s}^{2}}\right)\left(1-\frac{w^{2}}{w_{p}^{2}}\right)-w^{2} L_{2} C_{2}}{j w C_{2}\left(1-\frac{w^{2}}{w_{p}^{2}}\right)}$

The series resonance frequency $\left(w_{s}\right)$ and parallel resonance frequency $\left(w_{p}\right)$ in radians can be expressed as:

$w_{s}=\frac{1}{\sqrt{L_{1} C_{1}}} ; w_{p}=\frac{1}{\sqrt{L_{2} C_{2}}}$

Let, $w_{a}, w_{b}$ are the resonant frequencies of two single tuned passive filters.

$w_{a}=\frac{1}{\sqrt{L_{a} C_{a}}} ; w_{b}=\frac{1}{\sqrt{L_{b} C_{b}}}$ 
The impedance of two parallel single tuned filters can be expressed as:

$$
Z_{a b}=\frac{\left(1-\frac{w^{2}}{w_{a}^{2}}\right)\left(1-\frac{w^{2}}{w_{b}^{2}}\right)}{j w c_{a}\left(1-\frac{w^{2}}{w_{b}^{2}}\right)+j w c_{b}\left(1-\frac{w^{2}}{w_{a}^{2}}\right)}
$$

The cumulative impedance of double tuned filter is same as cumulative impedance of two single tuned passive filters [4].

$Z=Z_{a b}$

Comparing coefficient of $w^{4}$

$w_{a} w_{b}=w_{s} w_{p}$

Comparing coefficient of $w$

$C_{1}=C_{a}+C_{b}$

Comparing coefficient of $w^{3}$

$C_{b} \frac{1}{w_{a}^{2}}+C_{a} \frac{1}{w_{b}^{2}}=C_{1} \frac{1}{w_{p}^{2}}$

The parameter $L_{l}$ is given by

$L_{1}=\frac{1}{C_{a} w_{a}^{2}+C_{b} w_{b}^{2}}$

The series resonance frequency $w_{s}$ and parallel resonance frequency $w_{p}$ of double tuned filter can be obtained by

$w_{s}=\frac{1}{\sqrt{L_{1} C_{1}}}$

$w_{p}=\frac{w_{a} w_{b}}{w_{s}}$

Since, $w_{a}$ is the zero of double tuned filter impedance, so $\mathrm{Z}\left(w_{a}\right)=0$. The equation to solve $L_{2}$ is

$\left(1-\frac{w_{a}^{2}}{w_{s}^{2}}\right)\left(1-\frac{w_{a}^{2}}{w_{p}^{2}}\right)-w^{2} L_{2} C_{1}=0$

The above equation can be simplified to get $L_{2}$ 


$$
L_{2}=\frac{\left(1-\frac{w_{a}{ }^{2}}{w_{s}{ }^{2}}\right)\left(1-\frac{w_{a}^{2}}{w_{p}^{2}}\right)}{C_{1} w_{a}{ }^{2}}
$$

The value of $C_{2}$ can be obtained by

$C_{2}=\frac{1}{L_{2} w_{p}^{2}}$

Hence all the parameters needed for double tuned filter $\left(L_{1}, C_{1}, L_{2}, C_{2}\right)$ can be calculated from the parameters of two parallel connected single tuned filters $\left(L_{a}, C_{a}, L_{b}, C_{b}\right)$.

This double tuned passive power filter can provide better performance in eliminating lower order current harmonics than two single tuned passive filters. The size of double tuned passive filter is less as compared to single tuned passive filter and also the reactive power requirement is less [4]. Hence double tuned passive filter is the best choice for eliminating lower order current harmonics.

\section{Design of Series Active Power Filter}

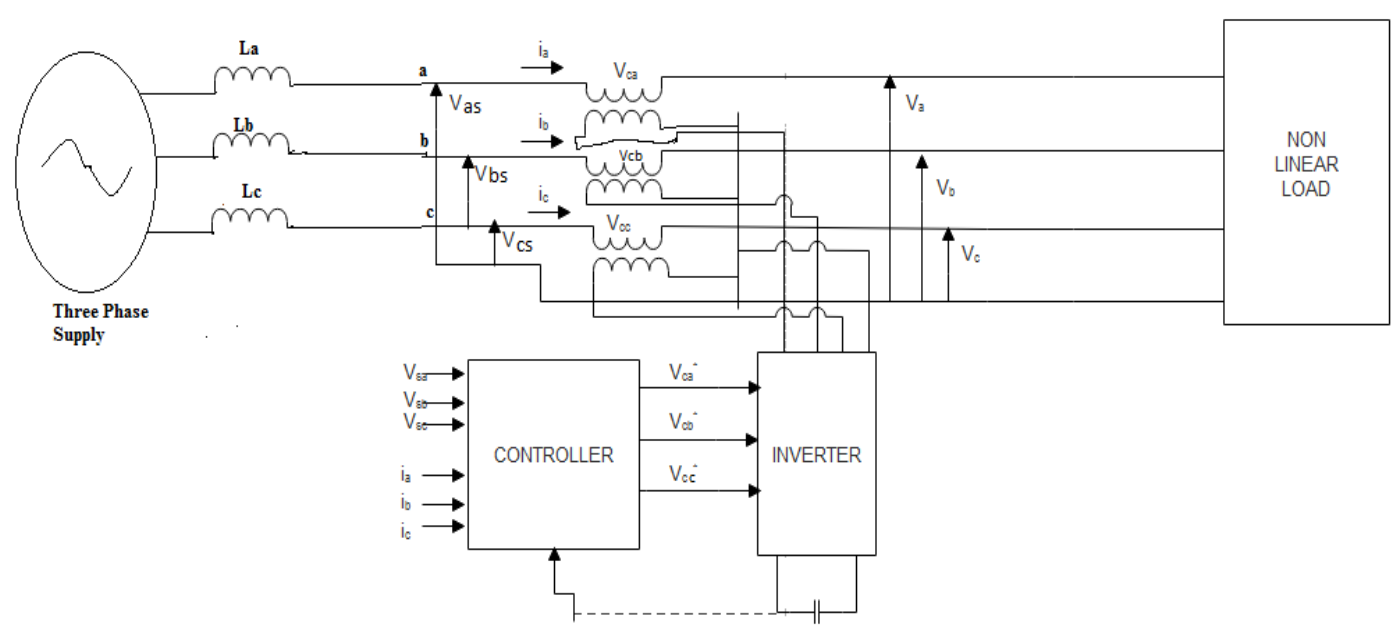

Figure 4. Series Active Power Filter

\subsection{Instantaneous Power (p-q) Theory:}

Series active power filter shown in Figure 4 is as like as the shunt active power filter except three isolation transformers, and it is able to reduce harmonics in the source voltages and the voltages applied to the load should be purely sinusoidal (reducing voltage harmonics) [5]. The series active filter consists of a voltage-source inverter (input side capacitor and outputside inductor) and requires three single-phase isolation transformers with suitable kVA rating . The series active filter is not useful to eliminate current harmonics but it provides high-impedance to the current harmonics from nonlinear load. In this proposed research, the ultimate aim is to supply the sisnusoidal voltages $\left(V_{a}, V_{b}, V_{c}\right)$ to the different loads connected to the same supply.

The scientist Akagi et. al., in 1983 have derived and proposed the "Theory of the Instantaneous Reactive Power in a-b-c Circuits", also known as instantaneous power 
theory, or p-q theory [5]. The p-q theory works on instantaneous values in a-b-c power systems without or with neutral wire. It is useful for both steady-state and transient operations and also it is useful for improvement of source voltage and current waveforms [5]. The p-q theory involves an algebraic transformation (Clarke transformation) of the voltages and currents in the a-b-c coordinates to the $\alpha-\beta-0$ coordinates [6], the calculations are given by

$$
\begin{aligned}
& {\left[\begin{array}{l}
V_{0} \\
V_{\alpha} \\
V_{\beta}
\end{array}\right]=\sqrt{\frac{2}{3}}\left[\begin{array}{ccc}
\frac{1}{\sqrt{2}} & \frac{1}{\sqrt{2}} & \frac{1}{\sqrt{2}} \\
1 & -\frac{1}{2} & -\frac{1}{2} \\
0 & \frac{\sqrt{3}}{2} & -\frac{\sqrt{3}}{2}
\end{array}\right] \cdot\left[\begin{array}{l}
V_{a s} \\
V_{b s} \\
V_{c s}
\end{array}\right]} \\
& {\left[\begin{array}{l}
i_{0} \\
i_{\alpha} \\
i_{\beta}
\end{array}\right]=\sqrt{\frac{2}{3}}\left[\begin{array}{ccc}
\frac{1}{\sqrt{2}} & \frac{1}{\sqrt{2}} & \frac{1}{\sqrt{2}} \\
1 & -\frac{1}{2} & -\frac{1}{2} \\
0 & \frac{\sqrt{3}}{2} & -\frac{\sqrt{3}}{2}
\end{array}\right] \cdot\left[\begin{array}{l}
i_{a} \\
i_{b} \\
i_{c}
\end{array}\right]}
\end{aligned}
$$

The zero-sequence instantaneous real power is given by

$$
p_{0}=V_{0} i_{0}
$$

The instantaneous real power in $\alpha-\beta$ coordinates is given by

$$
p=V_{\alpha} i_{\alpha}+V_{\beta} i_{\beta}
$$

The instantaneous imaginary power in $\alpha-\beta$ coordinates is given by

$q=V_{\alpha} i_{\beta}-V_{\beta} i_{\alpha}$

The $p$ and $q$ in the form of $\alpha-\beta$ coordinates of voltages and currents is given by

$$
\left[\begin{array}{l}
p \\
q
\end{array}\right]=\left(\begin{array}{cc}
V_{\alpha} & V_{\beta} \\
-V_{\beta} & V_{\alpha}
\end{array}\right) \cdot\left[\begin{array}{l}
i_{\alpha} \\
i_{\beta}
\end{array}\right]
$$

$\overline{p_{0}}=$ average quantity of the instantaneous zero-sequence real power which corresponds to the energy per unit time which is coming from the source to the load via the $V_{0} \& i_{0}[6]$.

$\tilde{p}_{0}=$ changed quantity of the instantaneous zero-sequence real power which means that the energy per unit time that is exchanged among the source and the load via the zero-sequence values. The zero-sequence power avaible in three-phase systems with only neutral wire. In order to have zero sequence components, the systems must have 
unbalanced voltages and currents and/or $3^{\text {rd }}$ harmonics in both voltage and current of at least any of one phase [7]. The power flow diagram is shown in Figure 5 indicates the flow of various power quantities such as

$\bar{p}=$ average quantity of the instantaneous real power which corresponds to the energy per unit time which is coming from the source to the load, via the a-b-c coordinates, in a balanced way i.e., only positive sequence [8].

$\tilde{p}=$ changed quantity of the instantaneous real power which is the energy per time unity that is circulating between the source and the load, via the a-b-c coordinates [9].

$q=$ instantaneous reactive power which belongs to the power that is circulated between the lines(L-L) of the load( H. Akagi \& A. Nabae, 1993). This component does not involves any circulation or exchange of energy between the source and the load, but it is indication of the availability of unwanted currents circulate between the phases. For a balanced sinusoidal voltage supply and a balanced load, with or without harmonics, $q$ (the mean value of the instantaneous imaginary power) is equal to the conventional reactive power [10].

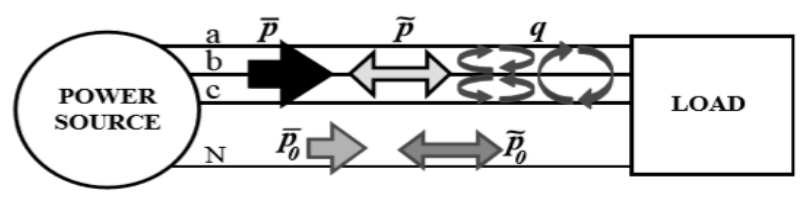

Figure 5. Power Flow Diagram

The instantaneous theory is one of the best method that can be used in the control series active filters . The important features of $p$-q theory are:

It is inbuilt a three-phase theory; It is applicable to any a-b-c system like balanced, unbalanced and with or without harmonics for source voltage and current waveforms) [11]; It works on instantaneous powers, gives an excellent stedy state and dynamic response and also it can be applied to variable non-linear loads [12]; the calculations are very simple (it only requires algebraic equations that must be incorporated using standard processors); It permits two control strategies: constant instantaneous supply power and sinusoidal supply current [13]. In this proposed research constant instantaneous supply power theroy was used.

\section{2. p-q Theroy Applied to Series Active Power Filters:}

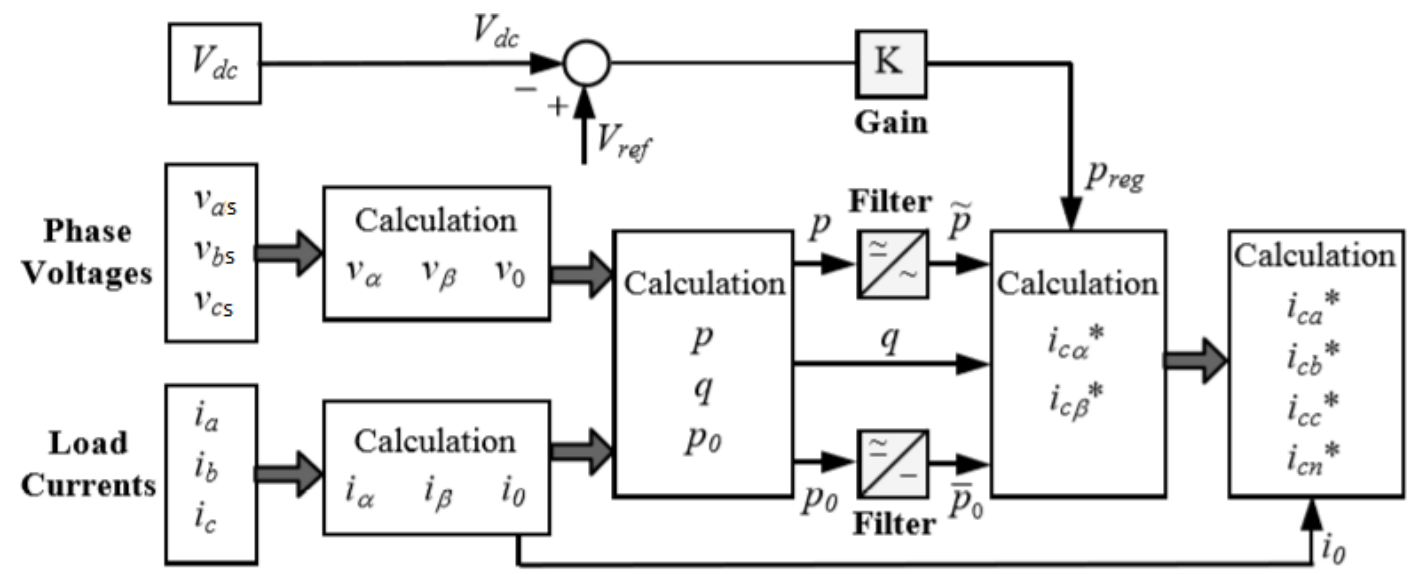

Figure 6. Control Circuit of Series Active Filter 
Instantaneous $\mathrm{p}-\mathrm{q}$ control theory was applied to the voltage series active power filter to eliminate voltage harmonics in distributed power system under non-linear conditions. Filter series allows to eliminate voltage harmonics of supply points where voltage is nonsinusoidal and to supply the user with sinusoidal voltage. The $\mathrm{p}-\mathrm{q}$ technique is divided into three stages as shown in Figure 6. The first stage is the sensing of essential voltage and current signals with power transformers and current transformers to gather exact power system information [14]. The second stage involves deriving compensating commands in terms of current or voltage levels based on filter configuration and control methods [14]. The third stage of control used to derive the necessary gating signals for the Mosfet or IGBT of the active filter using hysteresis control techniques [15]. The instantaneous $\mathrm{p}-\mathrm{q}$ theory is used for deriving the compensating signal.

The compensating voltage signals can be generated by using $\mathrm{p}$-q theory followed by the equations as

Since the system chosen is balanced in nature so zero sequence components can be neglected. The instantaneous real and reactive powers in $\alpha-\beta$ coordinates are given by

$$
\begin{aligned}
& {\left[\begin{array}{l}
p \\
q
\end{array}\right]=\left[\begin{array}{cc}
i_{\alpha} & i_{\beta} \\
-i_{\beta} & i_{\alpha}
\end{array}\right] \cdot\left[\begin{array}{l}
V_{\alpha} \\
V_{\beta}
\end{array}\right]} \\
& {\left[\begin{array}{l}
V_{\alpha}{ }^{*} \\
V_{\beta}^{*}
\end{array}\right]=\frac{1}{i_{\alpha}{ }^{2}+i_{\beta}{ }^{2}}\left[\begin{array}{cc}
i_{\alpha} & -i_{\beta} \\
i_{\beta} & i_{\alpha}
\end{array}\right]\left[\begin{array}{l}
\tilde{p}-\overline{p_{0}} \\
q
\end{array}\right]} \\
& V_{0}^{*}=V_{0} \\
& {\left[\begin{array}{c}
V_{c a}^{*} \\
V_{c b}^{*} \\
V_{c c}^{*}
\end{array}\right]=[C]^{-1}\left[\begin{array}{c}
V_{0} \\
V_{\alpha} \\
V_{\beta}
\end{array}\right]} \\
& \text { Where }[C]=\sqrt{\frac{2}{3}}\left[\begin{array}{ccc}
\frac{1}{\sqrt{2}} & \frac{1}{\sqrt{2}} & \frac{1}{\sqrt{2}} \\
1 & -\frac{1}{2} & -\frac{1}{2} \\
0 & \frac{\sqrt{3}}{2} & -\frac{\sqrt{3}}{2}
\end{array}\right]
\end{aligned}
$$

\section{Results and Discussion}

\subsection{Without Filter}

When the power system is connected to a non-linear load, there is a generation of harmonics, which disturb the source voltage and current waveforms. The harmonic disturbance in voltage and current waveform is expressed in terms of Total Harmonic Distortion (THD). The THD of source voltage and source current without having any power filter is given in Figure $8 \& 10$ and corresponding waveforms are shown in Figure $7 \& 9$. 


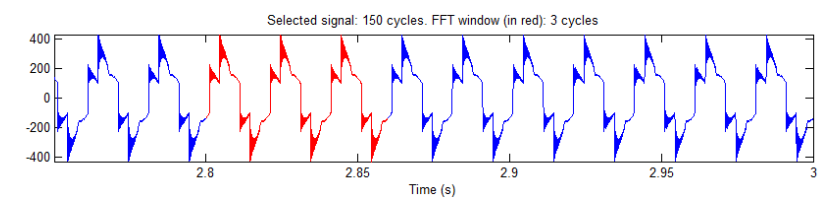

Figure 7. Source Voltage

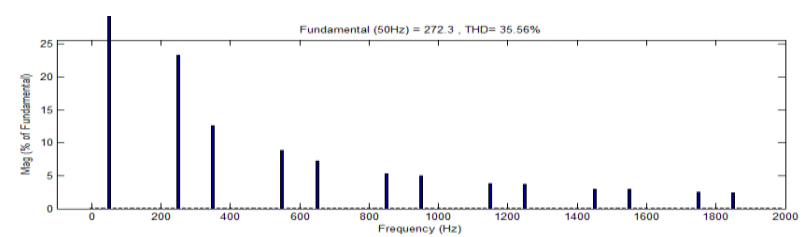

Figure 8. THD of Source Voltage

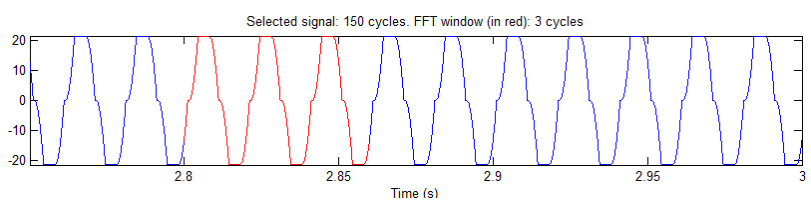

Figure 9. Source Vurrent

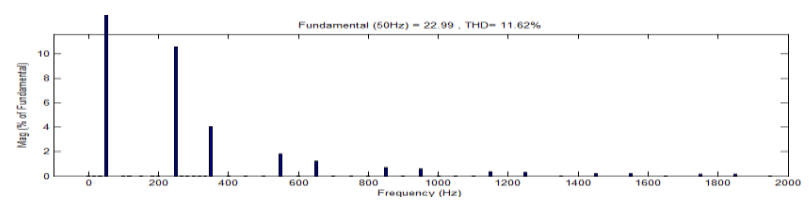

Figure 10. THD of Source Current

\subsection{With Double Tuned Passive Filter}

The double tuned filter provides effective elimination of lower order current harmonics than higher order current harmonics and also it eliminates some voltage harmonics as shown in Figure $12 \& 14$ and corresponding waveforms are shown in Figure $11 \& 13$.

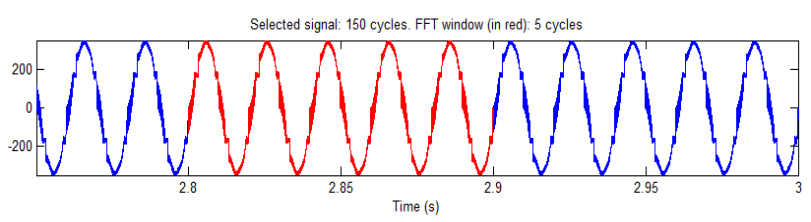

Figure 11. Source Voltage

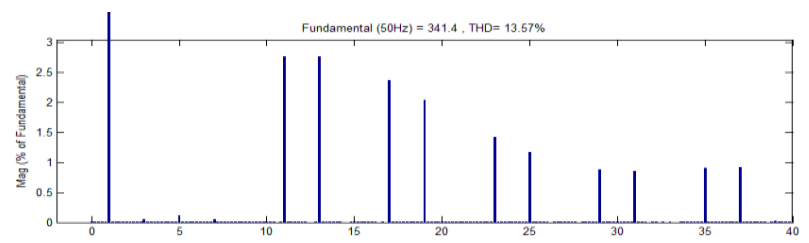

Figure 12. THD of Source Voltage 


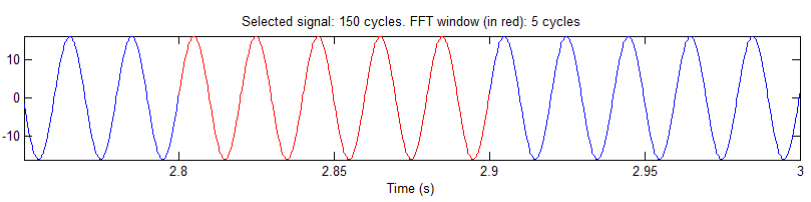

Figure 13. Source Current

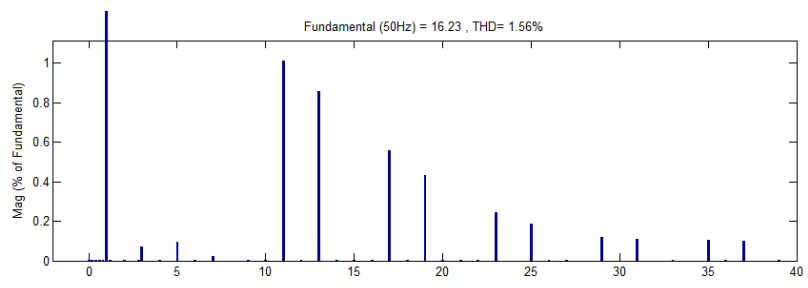

Figure 14. THD of Source Current

\subsection{With series active power filter}

The series active power filter provides effective elimination of voltage harmonics as shown in Figure16, but it is not so effective in eliminating current harmonics as shown in Figure 18. The waveforms of source voltage and current are shown in Figure $15 \& 17$.

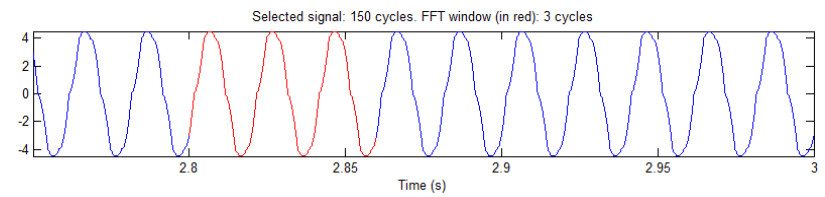

Figure 15. Source Voltage

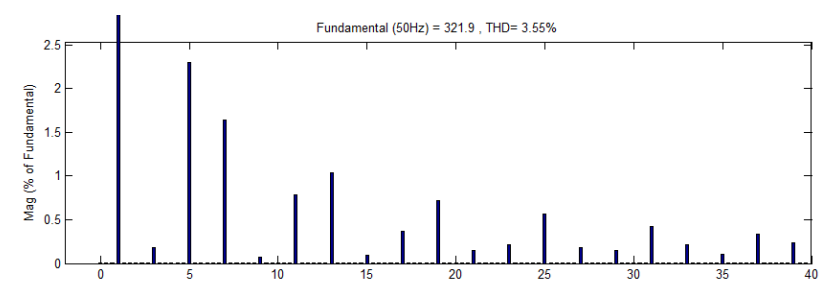

Figure 16. THD of Source Voltage

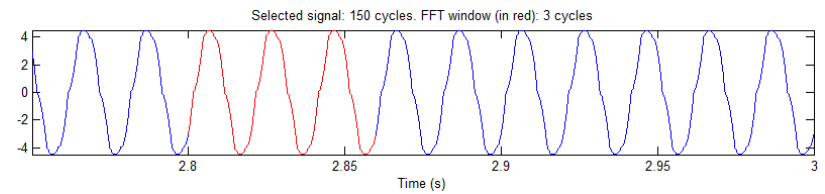

Figure 17. Source Current

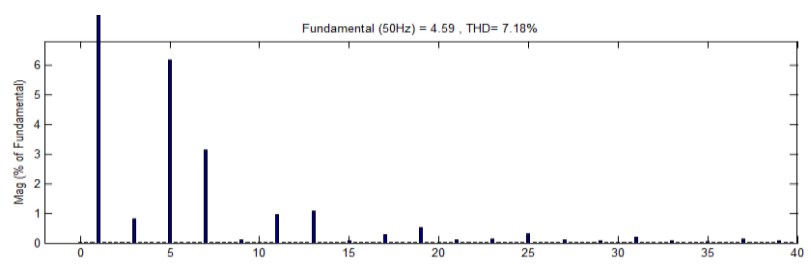

Figure 18. THD of Source Current 


\subsection{With Series Hybrid Active Power Filter}

Series hybrid active power filter provides effective elimination of both voltage and current harmonics as compared to series active and double tuned passive filter alone as shown in Figure $20 \& 22$ and corresponding waveforms are shown in Figure 19 \& 21.

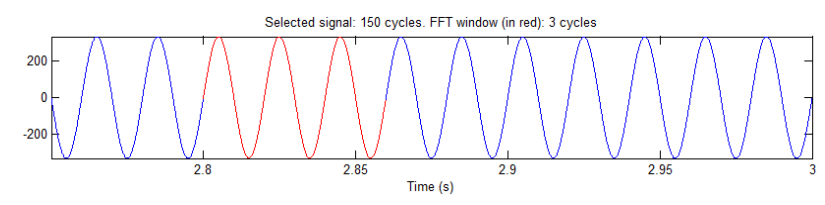

Figure 19. Source Voltage

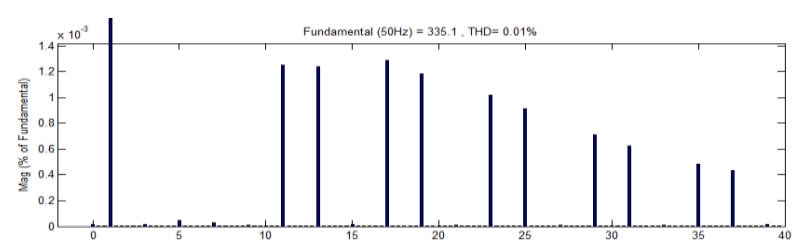

Figure 20. THD of Source Voltage

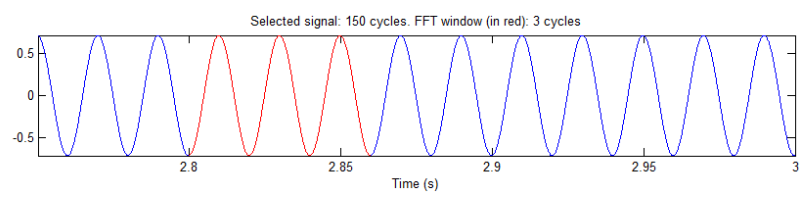

Figure 21. Source Current

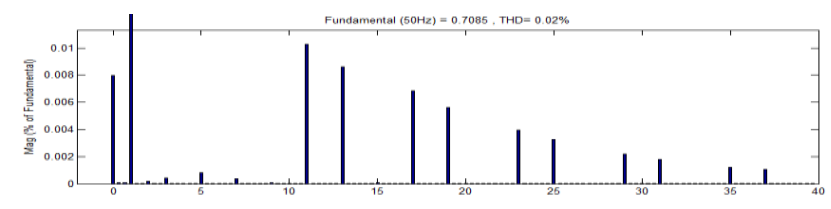

Figure 22. THD of Source Current

\section{Conclusions}

From the MATLAB Simulink results, it can be concluded that series hybrid active power filter is an excellent device for eliminating both voltage and current harmonics than series active filter and double tuned passive filter, especially it is more useful in improving voltage quality in a three phase distribution system in order protect the sensitive loads from the voltage and current harmonics. As of now, only shunt active power filter is commercially available in the market so, there is future research scope on developing hardware model of a series hybrid active power filter. Instantaneous power theory ( $\mathrm{p}-\mathrm{q}$ ) can be applied to eliminate current and voltage harmonics for balanced, unbalanced and transient conditions. The performance of series hybrid active power filter for higher voltage rating can be improved by implementing multi-level inverter with suitable control strategy. 
Table 1. Parameters of Series Hybrid Active Power Filter

\begin{tabular}{cc}
\hline Parameters & Value \\
\hline $\begin{array}{c}\text { Three Phase Power Supply } \\
\left(\mathrm{V}_{\mathrm{sPh}-\mathrm{Ph}}, \mathrm{f}, \mathrm{R}_{\mathrm{s}}, \mathrm{L}_{\mathrm{s}}\right)\end{array}$ & $415 \mathrm{~V}, 50 \mathrm{~Hz}, 0.8929 \Omega, 16.5 \mathrm{mh}$ \\
\hline $\begin{array}{c}\text { Load Resistance }\left(\mathrm{R}_{\mathrm{L}}\right) \& \\
\text { Inductance }\left(\mathrm{L}_{\mathrm{L}}\right)\end{array}$ & $100 \Omega, 80 \mathrm{mh}$ \\
\hline $\begin{array}{c}\text { Coupling Transformer } \\
\left(\mathrm{KVA}, \mathrm{V}_{(\mathrm{Ph}-\mathrm{Ph})}, \text { turns ratio, winding }\right. \\
\text { resistance }(\mathrm{R}) \text { and inductance }(\mathrm{L})\end{array}$ & $1 \mathrm{kVA}, 500 \mathrm{~V}, 1: 1,0.05 \Omega, 1 \mathrm{~h}$ \\
\hline
\end{tabular}

Table 2. THD Levels of Different Harmonic Filters

\begin{tabular}{ccc}
\hline Type of Filter & $\begin{array}{c}\text { THD of Source } \\
\text { Voltage }\end{array}$ & $\begin{array}{c}\text { THD of Source } \\
\text { Current }\end{array}$ \\
\hline Without filter & 35.56 & 11.62 \\
\hline $\begin{array}{c}\text { Double tuned passive power } \\
\text { filter }\end{array}$ & 13.57 & 1.56 \\
\hline Series active power filler & 3.55 & 7.18 \\
\hline $\begin{array}{c}\text { Series hybrid active power } \\
\text { filter }\end{array}$ & 0.01 & 0.02 \\
\hline
\end{tabular}

\section{Acknowledgements}

The authors are highly acknowledged J.N.T.U, Kakinada and S.V.E.C, Tirupathi for giving research support and encouragement during the $\mathrm{Ph}$. D programme.

\section{References}

[1] H. Akagi, Y. Kanazawa and A. Nabae, "Generalized Theory of the Instantaneous Reactive Power in Three-Phase Circuits”, IPEC'83 - Int. Power Electronics Conf., Tokyo, Japan, (1983), pp. 1375-1386.

[2] H. Akagi, Y. Kanazawa and A. Nabae, "Instanataneous Reactive Power Compensator Comprising Switching Devices without Energy Storage Compenents”, IEEE Trans. Industry Applic., vol. 20, (1984) May/June.

[3] H. Yi-hong and S. Heng, "A New Method of Designing Double -tuned Filter", Proceedings of the $2^{\text {nd }}$ international conference on computer science and electronics engineering (ICCSEE 2013).

[4] X. Yao, "Algorithm for the Parameters of Double tuned Filter [J]", USA: IEEE, vol. 1, (1998), pp. 154157.

[5] H. Akagi, "New trends in active filters for power conditioning", IEEE Trans. on Ind. Appl., vol. 32, no. 6, (1996), pp. 1312-1322.

[6] J. Afonso, C. Couto and J. Martins, "Active Filters with Control Based on the p-q Theory", IEEE Industrial Electronics Society Newsletter, ISSN: 0746-1240, vol. 47, no. 3, (2000) Sept., pp. 5-10.

[7] B. Singh, K. Al-Haddad and A. Chandra, "A Review of Active Filters for Power Quality Improvement”, IEEE Trans. Ind. Applicat., vol. 46, no. 5, (1999) October, pp. 960-971.

[8] R. C. Dugan, Mark, F. McGranaghan, S. Santoso and H. Wayne Beaty, "Electrical Power Systems Quality", Tata Mcgrw-hill $3^{\text {rd }}$ edition.

[9] M. El-Habrouk, M. K. Darwish and P. Mehta, "Active power filters: a review", IEE Proc. EPA, vol. 147, no. 5, (2000), pp. 403-413.

[10] S. Rechka, E. Ngandui, J. Xu and P. Sicard, "A comparative study of harmonic detection algorithms for active filter and hybrid active filers", IEEE Power Elec. Specialist Conf., (2002), pp. 357-363.

[11] H. Akagi and A. Nabae, "The p-q theory in three-phase systems under non-sinusoidal conditions", European Transaction on Electric Power, vol. 3, (1993), pp. 27-31.

[12] K. R. Cheepati, S. Ali and M. S. Kalavathi, "Implementation Of Shunt Hybrid Active Filter (Shaf) For Power Quality Improvement With Fuzzy Logic Controller To Mitigate Current Harmonics”, IJEEE, vol. 7, Issue: 02, (2015), pp. 1-10.

[13] S. Kothuru, J. Kothuru and K. Reddy.CH, "Reduction of Harmonics in 3-Phase, 3-Wire System by the Use of Shunt active filter", International Conference on Circuit, Power and Computing Technologies [ICCPCT], (2014). 
[14] K. R. Cheepati and T. N. Prasad, "Performance Comparison of Short Term Load Forecasting Techniques", International Journal of Grid and Distributed Computing, vol. 9, no. 4, (2016), pp. 287302.

[15] K. R. Cheepati, S. Ali and M. Surya Kalavathi, "Performance Analysis of Double Tuned Passive Filter for Power Quality", International Journal of Control Theory and Applications, vol. 9, Issue: 07, (2016), pp. 3295-3305.

\section{Authors}

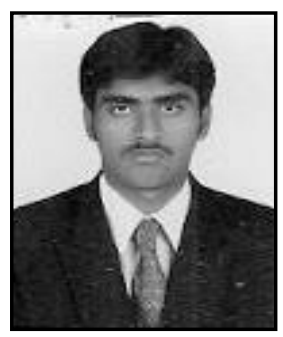

Kumar Reddy Cheepati, was born in Kadapa, A.P, India Country. He received his M. Tech from V.T.U, Belgaum in 2011. Currently he is working as a Asst. Professor at S.V.E.C, Tirupathi and pursuing Ph.D at J.N.T.U, Kakinada. His research interests include Power Quality, FACTS, Deregulation, Multi-level inverters and High Voltage Engineering.

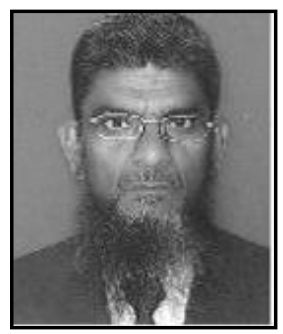

Sardar Ali, received his Ph.D from JNTUA, Ananthapur, India. Currently he is working as a Principal at RITS, Chevella. His research interests include Power Quality, FACTS, Deregulation, Multi-level inverters and High Voltage Engineering. He published more than 20 journals in various national and international journals.

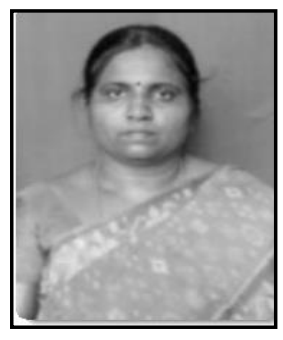

Surya Kalavathi M, working as a Professor at JNTU College of Engineering, JNTU, Hyderabad. She has published more than 100 Research Papers in international and nataional journals. She has guided $9 \mathrm{Ph} . \mathrm{D}$ scholars and presently guiding $5 \mathrm{Ph}$.D. Scholars. She has specialised in Power Systems, High Voltage Engineering and Control Systems. Her research interests include Simulation studies on Transients of different power system equipment. She has 24 years of experience. She has invited for various lectures in institutes. 